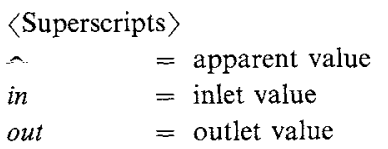

Literature Cited

1) Dryden, C. E., D. A. Strang and A. E. Withrow: Chem. Eng. Progr., 49, 191 (1953).

2) Happel, J.: AIChE J., 4, 197 (1958).

3) Hikita, H., K. Ishimi and K. Kubo: Chem. Eng. Commun., 17, 239 (1982).
4) Kataoka, T., H. Yoshida and K. Ueyama: J. Chem. Eng. Japan, 5, 132 (1972).

5) Kubo, K., T. Aratani and A. Mishima: Kagaku Kogaku Ronbunshu, 7, 304 (1981).

6) Pfeffer, R.: Ind. Eng. Chem. Fundam., 3, 380 (1964).

7) Williamson, J. E., K. E. Bazaire and C. J. Geankoplis: Ind. Eng. Chem. Fundam., 2, 126 (1963).

8) Wilson, E. J. and C. J. Geankoplis: Ind. Eng. Chem. Fundam., $5,9(1966)$.

\title{
MOISTURE PROFILE OF UNGLAZED ALUMINA-BASED CERAMIC ON CONVECTION DRYING
}

\author{
HIRONOBU IMAKOMA, MORIO OKAZAKI AND RYOZO TOEI \\ Department of Chemical Engineering, Kyoto University, Kyoto 606
}

Key Words: Convection Drying, Nonhygroscopic Material, Drying Model, Moisture Profile, Water Movement Model

\section{Introduction}

To express the water movement in an unsaturated porous body, we have proposed a modified KozenyCarman equation originating from the capillary action. ${ }^{3,7)}$ This equation was applied to the movement of condensed water in fine capillaries in an adsorptive porous body and it was found that the Kozeny constant varies inversely with the ratio of the amount of condensed water to the total moisture content: $K_{c} \propto X^{*} / X_{1}{ }^{8)}$ This relation was confirmed by comparing the experimental drying data of an activated alumina rod with the calculated value. ${ }^{9)}$

The object of this study is to confirm whether this simple relation can be applied to the movement of liquid water in fine capillaries in a non-hygroscopic porous body on drying, and to simulate the drying process using this water movement model and the drying model proposed by the authors. ${ }^{7)}$

\section{Experimental Results}

The model material employed is an unglazed alumina-based ceramic. The experimental details are described in the previous study. ${ }^{6}$ Figure 1 indicates the cumulative curves of the pore volume and the surface area determined by the mercury penetration technique. The moisture content, $X$, can be calculated

Received Octobes 3, 1984. Correspondence concerning this article should be addressed to H. Imakoma. by the equation $X=\rho_{l}\left(V_{t}-V\right)$, using the cumulative pore-volume distribution, $V$, in this figure.

Figures 2 and 3 illustrate the experimental results. As may be seen from Fig. 3, the drying process was isothermal during all the period of drying except $t<2 \mathrm{~h}$ in this experiment.

The critical moisture content was established during $5 \mathrm{~h}<t_{c}<6 \mathrm{~h}$ and the surface moisture content at this point $X_{c} / X^{*}$ was 0.22 (see Fig. 2). The value of $S_{c}$ determined from Fig. 1 is $1.09 \times 10^{2} \mathrm{~m}^{2} \cdot \mathrm{kg}^{-1}$. The value of $X_{c}$ is equivalent to the maximum amount of unremovable pendular water.

\section{Theory}

It was found that liquid water in a non-hygroscopic capillary porous body classified into two groups ${ }^{5}$ : funicular water capable of flowing in liquid state

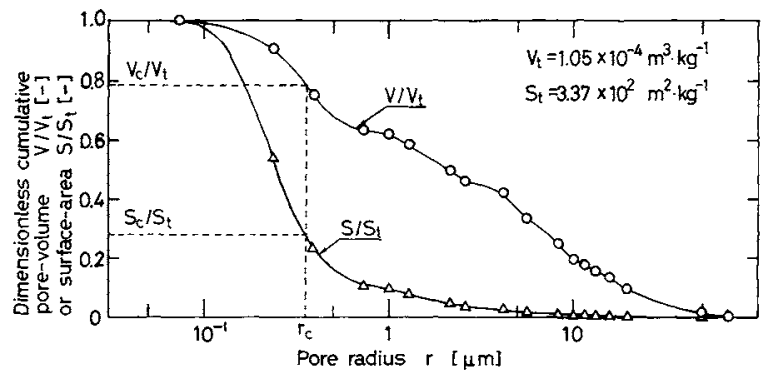

Fig. 1. Cumulative curves of pore volume and surface area. (Unglazed alumina-based ceramic.) 


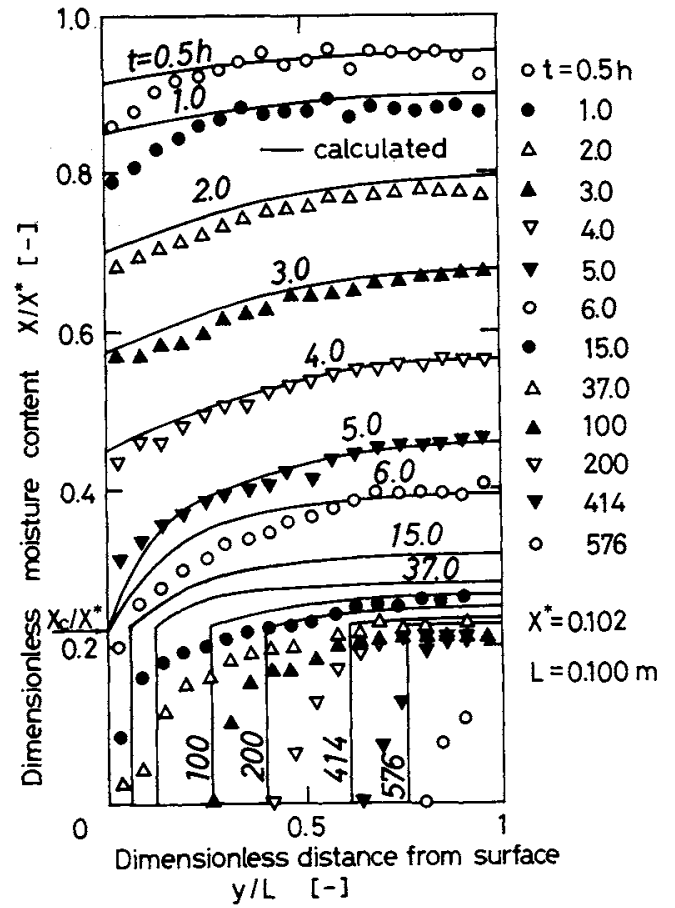

Fig. 2. Moisture content profiles. (Unglazed alumina-based ceramic; $38^{\circ} \mathrm{C}$.)

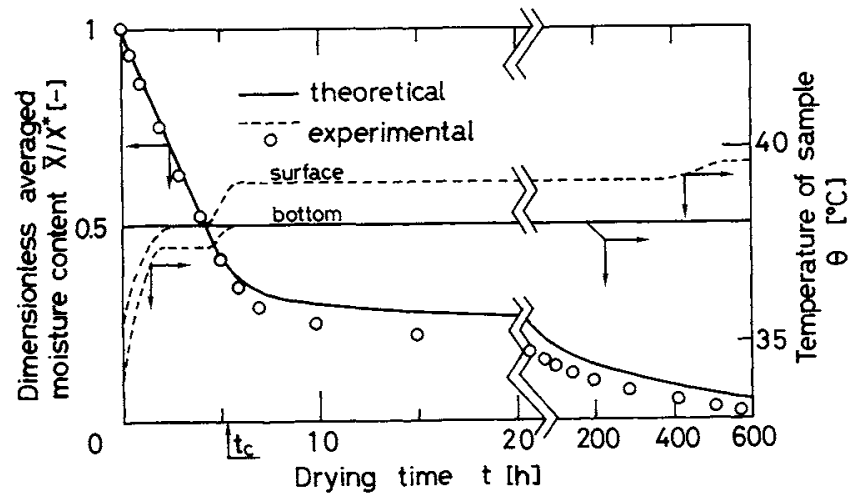

Fig. 3. Drying curve and temperature change of sample with time. (Unglazed alumina-based ceramic; $38^{\circ} \mathrm{C}$.)

$\left(X_{c}<X \leqq X^{*}\right)$, and pendular water that evaporates on the spot and moves in vapor state $\left(0<X \leqq X_{c}\right)$. In accordance with this fact, we proposed a mathematical model capable of describing the drying process of non-hygroscopic material. ${ }^{7)}$ Since the experimental drying process is regarded as an isothermal one, the following mathematical expressions are derived under an isothermal condition. The mathematical analysis of the drying problem is divided into the constant-rate and the receding-front (falling-rate) periods.

During the period of constant drying rate the capillary potential causes almost all the liquid water to move toward the surface, where it evaporates, and vapor transfer within the body can be ignored. If the liquid flow of the funicular water in the body due to the gradient in the capillary pressure is expressed in terms of the modified Kozeny-Carman equation derived for the condensed water in an adsorptive porous material and proposed in the previous study, ${ }^{8)}$ the flux is given by*

$$
\begin{aligned}
J_{l}=- & \rho_{\text {sapp }} D_{l} \frac{d X}{d y} \\
=- & \rho_{\text {sapp }} D_{l 0}\left(\frac{T}{T_{0}}\right)\left(\frac{\mu_{l 0}}{\mu_{l}}\right)\left(\frac{S_{c}}{S_{c}-S}\right)^{2}\left(\frac{X-X_{c}}{X^{*}-X_{c}}\right)^{4} \\
& \quad \times\left(1 / p_{v}\right) \frac{d p_{v}}{d X} \frac{d X}{d y}
\end{aligned}
$$

The constant $D_{l 0}$ of Eq. (1) can be estimated by use of the reference value of liquid water transfer coefficient at the known value of moisture content at a selected temperature of $T_{0}$. Figure 4 illustrates the relationship between the values of experimental $D_{l}$ calculated from the experimental data of the moisture content distribution as a function of time ${ }^{6)}$ and the curve of theoretical $D_{l}$ predicted by use of the value of experimental $D_{l}$ at $X / X^{*}=0.5$ as a reference value. As may be seen from the figure, the predicted curve agrees with the experimental values.

The constant-rate period continues till the value of surface moisture content becomes $X_{c}$, and the drying process in this period can be written mathematically as

$$
\begin{gathered}
\qquad \frac{\partial X}{\partial t}=\frac{\partial}{\partial y}\left(D_{l} \frac{\partial X}{\partial y}\right) \\
\text { I.C. } \quad X=X^{*} ; \quad 0 \leqq y \leqq L ; \quad t=0 \\
\text { B.C. } \quad \frac{\partial}{\partial t} \int_{0}^{L} \rho_{\text {sapp }} X d y=k_{g}\left(\left.p_{v}\right|_{0}-p_{v a}\right) ; \quad 0<t \leqq t_{c}
\end{gathered}
$$

$$
D_{l} \frac{\partial X}{\partial y}=0 ; \quad y=L ; \quad 0<t \leqq t_{c}
$$

where $p_{v} l_{0}$ can be regarded as the saturation value of $p_{v}$ at the temperature.

The surface moisture content falls to zero as soon as it reaches $X_{c}$ by our model, and this point is the beginning of the receding-front period. In this period

* The water held in an adsorptive porous body is divided into the adsorption water and the condensed water. The modified Kozeny-Carman equation was applied to the whole capillary condensed water and we found the relation

$$
K_{\mathrm{c}} \propto X^{*} / X_{l} .
$$

In the case of a non-hygroscopic body, however, as there exists no adsorption water, all the water held in the body is regarded as capillary water. It is assumed that the modified equation is applied only to the funicular water instead of the whole capillary condensed water. Consequently, the relation is expressed as

$$
K_{c} \propto\left(X^{*}-X_{c}\right) /\left(X-X_{c}\right) .
$$

Furthermore, as a vapor pressure depression in accordance with the Kelvin equation is caused in the fine capillaries, the capillary pressure and the vapor pressure are combined together by this equation. 


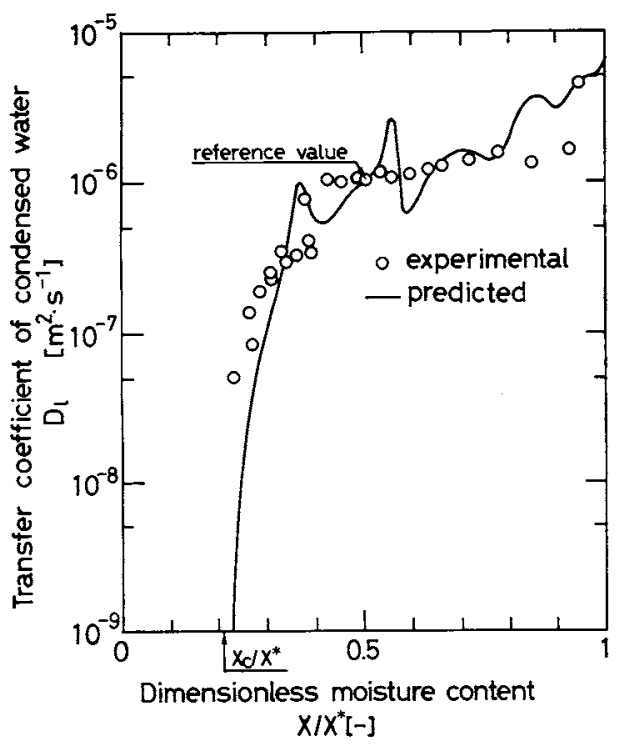

Fig. 4. Transfer coefficient of liquid water. (Unglazed alumina-based ceramic; $38^{\circ} \mathrm{C}$.)

the solid is divided into two zones: a dry zone $(0 \leqq y<\delta(t))$ and a wet zone $(\delta(t) \leqq y \leqq L)$. The mechanism of the water movement in the wet zone is the same as that in the constant-rate period. There is no liquid water in the dry zone, and treatment of the uniform-pressure diffusion is acceptable in this zone in the case of the employed material. The vapor flux can be consequently written as ${ }^{2)}$

$$
J_{v}=-\frac{M_{v} p_{t} D_{v a e}}{R T \alpha \delta} \ln \left\{\frac{1-\alpha\left(\left.p_{v}\right|_{0} / p_{t}\right)+\left(D_{v a e} / D_{K v e}\right)}{1-\alpha\left(\left.p_{v}\right|_{\delta} / p_{t}\right)+\left(D_{v a e} / D_{K v e}\right)}\right\}
$$

where $\alpha=1-\left(M_{v} / M_{a}\right)^{1 / 2}$.

The mathematical expression in this period is

$$
\frac{\partial X}{\partial t}=\frac{\partial}{\partial y}\left(D_{l} \frac{\partial X}{\partial y}\right)
$$

I.C.

$$
\left.X\right|_{0}=X_{c} ; \quad X=g(y) ; \quad t=t_{c}
$$

B.C.

$$
\begin{gathered}
\frac{\partial}{\partial t} \int_{\delta(t)}^{L} \rho_{\text {sapp }} X d y=-\left.J_{v}\right|_{\delta-}=-J_{v} ; \\
\left.X\right|_{\delta(t)}=X_{c} ; \quad t>t_{c} \\
-k_{g}\left(\left.p_{v}\right|_{0}-p_{v a}\right)=J_{v} ; \quad t>t_{c} \\
D_{l} \frac{\partial X}{\partial y}=0 ; \quad y=L ; \quad t>t_{c}
\end{gathered}
$$

where $X=g(y)$ of Eq. (7) is the final moisture content profile of the constant-rate period.

\section{Numerical Results and Discussion}

The drying model subject to the boundary conditions given by Eqs. (2)-(5) and (7)-(10) was solved

\begin{tabular}{|c|c|c|}
\hline$\rho_{\text {sapp }}$ & $2.79 \times 10^{3}$ & $\mathrm{~kg} \cdot \mathrm{m}^{-3}$ \\
\hline$S_{t}$ & $3.37 \times 10^{2}$ & $\mathrm{~m}^{2} \cdot \mathrm{kg}^{-1}$ \\
\hline$X^{*}$ & 0.102 , & $\mathrm{kg}$-water $\cdot \mathrm{kg}^{-1}$ \\
\hline$L$ & 0.100 & $\mathrm{~m}$ \\
\hline$k_{g}$ & $\begin{array}{l}1.55 \times 10^{-7} \\
\text { determined from } \\
\text { constant-rate peri }\end{array}$ & $\begin{array}{l}\mathrm{kg} \text {-water } \cdot \mathrm{m}^{-2} \cdot \mathrm{s}^{-1} \cdot \mathrm{Pa}^{-1} \\
\text { the drying rate of } \\
\text { iod }\end{array}$ \\
\hline$p_{v a}$ & $7.94 \times 10^{2}$ & $\mathrm{~Pa}$ \\
\hline$D_{K v e}$ & $\begin{array}{l}3.38 \times 10^{-6} \sqrt{T} \\
\text { obtained from th }\end{array}$ & $\begin{array}{l}\mathrm{m}^{2} \cdot \mathrm{s}^{-1} \\
\text { e permeation method }\end{array}$ \\
\hline$D_{v a e}$ & $\begin{array}{l}1.02 \times 10^{-15} T^{1.75} p_{t}^{1} \\
\text { obtained from th }\end{array}$ & $\begin{array}{l}\mathrm{m}^{2} \cdot \mathrm{s}^{-1} \\
\mathrm{e} \text { uniform-diffusion method } \\
{ }^{1)}\end{array}$ \\
\hline$D_{10}$ & $\begin{array}{l}1.31 \times 10^{-3} \\
\text { determined by th } \\
\text { experiment at } 38^{\circ}\end{array}$ & $\begin{array}{l}\mathrm{m}^{2} \cdot \mathrm{s}^{-1} \\
\text { e reference value of drying } \\
\mathrm{C}\end{array}$ \\
\hline
\end{tabular}
by an implicit finite difference technique at $38^{\circ} \mathrm{C}$. The calculation method for the constant-rate period involves the problem of finding the surface moisture content at $t=t+\Delta t$ by trial and error. It is more
Table 1. Physical characteristics and transport properties for drying of unglazed alumina-based ceramic

complicated to solve in the case of the receding-front period, because more trial-and-error calculations are required to solve Eqs. (8) and (9) for $J_{v}$ in the dry zone in addition to determining the value of $\delta$ as a function of $t$ by trial and error. The transport properties obtained by appropriate measurement methods and the physical characteristics of the material used to simulate the drying process are given in Table 1.

Figures 2 and 3 give comparisons of the simulation and experimental results. Agreement between the predicted values and experimental ones for the moisture content against time and position during the constant-rate period is satisfactory. This is because the relation $K_{c} \propto\left(X^{*}-X_{c}\right) /\left(X-X_{c}\right)$ can be applied to the non-hygroscopic material. Agreement during the receding-front period, however, is not so good. It is believed that the deviation can be ascribed to the assumption that the pendular water never moves in liquid state. Figure 2 also gives the positions of the receding front against time. The simulation results are in good agreement with the experimental data. This indicates that the diffusion coefficients determined from the measurement methods can estimate quantitatively the vapor flux in the dry zone.

\section{Conclusion}

The simple relation $K_{c} \propto X^{*} / X_{l}$ in the modified Kozeny-Carman equation proposed in the previous work ${ }^{8}{ }^{8}$ capable of describing the movement of the condensed water in an adsorptive porous material, is also valid for predicting the transport of the funicular water in a non-hygroscopic capillary porous body. In this case, however, this relation is rewritten as $K_{c} \propto\left(X^{*}-X_{c}\right) /\left(X-X_{c}\right)$.

The simple drying model ${ }^{7)}$ dividing the drying process into two parts predicts successfully the drying characteristics of the capillary porous body: the drying time for the constant-rate period and the position of the receding front as a function of time. 


\section{Acknowledgment}

The authors are grateful to Mr. Noritake Satake for his experimental assistance, and to the Ministry of Education, Science and Culture, Japan for the award of Grant-in-Aid for Scientific Research, No. 59750737 (1984).

\section{Nomenclature}

$D=$ transfer coefficient on the basis of moisture content gradient $\quad\left[\mathrm{m}^{2} \cdot \mathrm{s}^{-1}\right]$

$D_{K} \quad=$ Knudsen diffusion coefficient $\quad\left[\mathrm{m}^{2} \cdot \mathrm{s}^{-1}\right]$

$D_{l 0} \quad=$ parameter defined by Eq. (1) $\quad\left[\mathrm{m}^{2} \cdot \mathrm{s}^{-1}\right]$

$D_{v a} \quad=$ mutual diffusion coefficient $\quad\left[\mathrm{m}^{2} \cdot \mathrm{s}^{-1}\right]$

$J \quad=$ mass transfer flux $\quad\left[\mathrm{kg} \cdot \mathrm{s}^{-1} \cdot \mathrm{m}^{-2}\right]$

$K_{c} \quad=$ Kozeny constant $\quad[-]$

$k_{g} \quad=$ film mass transfer coefficient $\left[\mathrm{kg} \cdot \mathrm{Pa}^{-1} \cdot \mathrm{s}^{-1} \cdot \mathrm{m}^{-2}\right]$

$L \quad=$ length of sample [m]

$M \quad=$ molecular weight $\quad\left[\mathrm{mol} \cdot \mathrm{kg}^{-1}\right]$

$p \quad=$ pressure $[\mathrm{Pa}]$

$R \quad=$ gas constant $\quad\left[\mathrm{Pa} \cdot \mathrm{m}^{3} \cdot \mathrm{K}^{-1} \cdot \mathrm{mol}^{-1}\right]$

$S \quad=$ specific surface area $\quad\left[\mathrm{m}^{2} \cdot \mathrm{kg}^{-1}\right]$

$T \quad=$ temperature $[\mathrm{K}]$

$\begin{array}{lll}t & =\text { time } & \text { [s] or }[\mathrm{h}]\end{array}$

$V \quad=$ specific pore volume $\quad\left[\mathrm{m}^{3} \cdot \mathrm{kg}^{-1}\right]$

$X \quad=$ water content (dry basis) [-]

$y=$ cartesian coordinate perpendicular to solid surface

$=$ distance of dry zone

$=$ viscosity

$=$ density

$$
\begin{aligned}
& \text { a } \quad \text { air } \\
& \text { c } \quad=\text { critical } \\
& e \quad=\text { effective } \\
& l \quad=\text { liquid } \\
& \text { sapp } \quad=\text { apparent of solid } \\
& t \quad=\text { total } \\
& v \quad=\text { vapor }
\end{aligned}
$$

〈Superscript〉

$$
\text { * } \quad \text { saturated }
$$

\section{Literature Cited}

1) Asaeda, M., M. Okazaki and R. Toei: J. Chem. Eng. Japan, 7, 173 (1974).

2) Mason, E. A. and A. P. Malinauskas: "Gas Transport in Porous Media: The Dusty-Gas Model (Chemical Engineering Monographs Vol. 17)," p. 89, Elsevier Science Publishers B. V., Amsterdam (1983).

3) Tamon, H., M. Okazaki and R. Toei: AIChE J., 27, 271 (1981).

4) Tamon, H., S. Kyotani, H. Wada, M. Okazaki and R. Toei: $J$. Chem. Eng. Japan, 14, 136 (1981).

5) Toei, R., S. Hayashi, S. Sawada and T. Fujitani: Kagaku Kögaku, 29, 525 (1965).

6) Toei, R. and M. Okazaki: J. Eng. Phys., 19, 464 (Russian) (1970) [English edition: 19, 1123 (1970)].

7) Toei, R.: "Advances in Drying Vol. 2," p. 269, Hemisphere Pub. Corp., New York (1983).

8) Toei, R., H. Imakoma, H. Tamon and M. Okazaki: J. Chem. Eng. Japan, 16, 364 (1983).

9) Toei, R., H. Imakoma, H. Tamon and M. Okazaki: J. Chem. Eng. Japan, 16, 431 (1983).

〈Subscripts〉

$0 \quad=$ standard for $D_{l 0}$ 